\title{
Running events in Polish forests in the opinion of their participants
}

\author{
Emilia Janeczko ${ }^{1}$, Robert Tomusiak ${ }^{2}$, Małgorzata Woźnicka $\bowtie$, Krzysztof Janeczko $^{3}$ \\ ${ }^{1}$ Warsaw University of Life Sciences - SGGW, Faculty of Forestry, Department of Forest Utilization, Nowoursynowska \\ 159, 02-776 Warsaw, Poland, e-mail: woznickam@wl.sggw.pl \\ ${ }^{2}$ Warsaw University of Life Sciences - SGGW, Faculty of Forestry, Department of Dendrometry and Forest Productivity, \\ Nowoursynowska 159, 02-776 Warsaw, Poland \\ ${ }^{3}$ Warsaw University of Life Sciences - SGGW, Faculty of Forestry, Department of Forest Management and Economics \\ of Forestry, Nowoursynowska 159, 02-776 Warsaw, Poland
}

\begin{abstract}
The article presents the results of a questionnaire survey aimed at determining social preferences in relation to running as a form of active leisure time in forests. These preferences were established on the basis of surveys conducted via the Internet by means of social media services. The survey was carried out in 2016 and covered 346 people living in Poland, interested in running and jogging. It involved people over 18 years of age. As a research tool, an Internet questionnaire was used, which included questions concerning the attractiveness of the forest for practicing running, the frequency of running events in the forest, and factors motivating to take part in the running event. Statistical analysis was performed considering the influence of personal characteristics (gender, age, place of residence) and experience in running on the preferences of respondents with the use of the chi-square test. Men dominated among the respondents. The majority of respondents were people aged 35-44 living in towns. Over half of the respondents declared that they practiced athletic or recreational running for more than 4 years. The results show that the Polish forests are an attractive place for running. The preferences varied significantly, mainly in relation to gender, age, and experience in running. Age differentiated the views of respondents on the attractiveness of the forest as a place for running. Participating in forest running events was determined by gender, place of residence, and experience in running. Participants of such events are more frequently men, residing in towns. It was observed that the frequency of participation in running events increases with experience. The attractiveness of the running event was associated mainly with its general atmosphere and the characteristics of the running trail. However, the views were diversified according to gender, age, residence, and experience in running.
\end{abstract}

\section{KEY WORDS}

recreation, sport tourism, running events, forest environmental services 


\section{INTRODUCTION}

Nowadays, there is an increased awareness that movement, including sport and outdoor recreation, is not only advisable but also necessary for a healthy lifestyle. Sport, as well as natural recreation, facilitates the feeling of coexistence/integrity between humans and nature. Sports events trigger social activity, create conditions for cooperation, including competition, allowing for the development of social interactions in a group (overcoming obstacles, participation in discovery, etc.) (Moor and Wong 1997). The natural world provides strong sensory stimulation, which supports sensory integration (correct organization and interpretation of sensory sensations) and leads to correct brain development (Ayres 1979). Physical activity in a natural environment such as forests can bring much greater benefits to mental health than physical activity in any other place (Mitchell 2013). Scientific research shows that even short-term contact with the environment reduces attention-deficit hyperactivity disorder (ADHD). It facilitates work on focus and cognitive abilities (Faber 2001, Wells 2000). Gaining new sports experiences improve mood. Motivation and increased fitness enhance the sense of effectiveness and thus self-esteem (Swarbrick 2004). The growing popularity of running in forests and the interest in using forest areas for recreation and sports observed in recent years indicate the need for a deeper recognition of the needs and preferences of participants of sports events, including running in forests. Currently, preferences and expectations of various social groups in relation to tourism and recreation in forest areas are already well known (Hammitt and Patterson 1993; Janeczko 2002). However, there are not many studies that have determined in depth the behavior, expectations, and preferences of specific groups of users, such as forest runners or participants of forest sports events. Therefore, the results discussed in the paper significantly fill this gap and broaden the knowledge about the social and sports functions of the forest.

The article aims to address the question of whether forests are seen as an attractive place for the organization of sports events and also what factors determine the attractiveness of running events in Polish forests. The paper both describes and more importantly explains the preferences of sport and fitness runners within the context of events organized in Polish forests.

\section{MATERIAL AND METHODS}

An Internet questionnaire survey was used for establishing social preferences. Quantitative survey was carried out by means of the questionnaire available through the website www.webankieta.pl. The data were collected in the period from October to December 2016. The number of people participating in the study was a total of 346 persons aged 18 years and older. The survey was distributed through social networking sites (e.g., Facebook) among people interested in running. The postal invitations to the survey on social networking websites was aimed at reaching a very broad group of people, who practice running by participating in mass running events or as a leisure activity. The survey questionnaire consisted of two parts. The first part covered questions that concerned the characteristics of respondents (gender, age, and place of residence) and the so-called training experience. The second part of the survey comprised questions aimed at determining the respondents' views on the attractiveness of the forest as a place for the organization of sports events, factors determining the attractiveness of running events, and the participation of respondents in running events organized in Polish forests. All statistical analyses, performed with the use of a software package Statistica v. 13.0 (StatSoft, Inc.) at a 0.05 significance level, included the assessment of the independence of non-measurable characteristics calculated with the use of the chi-square test, which compared actual results obtained in the research with the expected values (theoretical). Statistical analyses allowed to verify the following hypotheses:

1. Opinions on the attractiveness of the forest as a place to sports, including the organization of running events are differentiated due to gender, age, place of residence and respondent's running experience.

2. There are differences in the assessment of factors determining the attractiveness of running events in Polish forests due to gender, age, place of residence and running experience of participants of these events.

In order to assess the strength of a relationship between two quantitative variables, the contingency coefficient was used, which can be applied in cross-tabulation with any number of levels of both variables. Its null value is interpreted as lack of correlation, whereas 
values close to 1 reveal a strong relationship between the variables.

\section{Results}

Data on gender, age, place of residence, and running experience of the respondents were presented in a different paper published by Janeczko et al (2018).

A vast majority of respondents (95.4\%) regard forests in Poland as an attractive place for running. Taking into consideration personal characteristics of the respondents, it was established that statistically views differed due to the different age of the respondents $(C=0.244, p=0.005)$. In all age groups, the conviction that forests are an attractive place for running was predominant. Such was the opinion of $97.5 \%$ of respondents aged $45-54,96.8 \%$ of respondents aged $35-44,96.5 \%$ of those aged $25-34$, and $88.2 \%$ of respondents aged $18-24$. The highest percentage $(81 \%)$ of those claiming that the forest is an attractive place for running constituted respondents older than 55 years, whereas a relatively high percentage $(9.5 \%)$ of people in this age group were of the opposite opinion. In the survey, $9.5 \%$ of people in this age group were unable to provide a definite opinion concerning the attractiveness of the forest as a place for running. In other age groups, the percentage of people regarding forests as unattractive place for running ranged from $0 \%$ among the respondents aged $45-54$ and $18-24$ up to $2.7 \%$ among those aged $25-34$ and $2.6 \%$ of the respondents aged $35-44$.

It was observed that $88.7 \%$ of respondents claimed that forests are suitable for organizing sports events, whereas $3.8 \%$ had no opinion and $7.5 \%$ were of the opposite view. Taking into account the influence of personal characteristics of respondents on their views on organizing running events in forests, it was established that those views differ statistically significantly due to the different age of the respondents $(C=0.302, p=0.004)$. The highest percentage of respondents (92.5\%) expressing the view that forests are the appropriate site for organizing sports events was observed in the group of respondents aged 45-55. Such was the opinion of $91.6 \%$ of respondents aged $35-54,88.5 \%$ of respondents aged $25-34,80.9 \%$ of those aged 55 and older, and $64.7 \%$ of respondents aged $18-24$. At the same time, the highest percentage (14.3\%) of the respondents claiming that forests are not suitable for the organization of running events was found among those older than 55 years. Compared to other age groups, the same view was indicated in $11.8 \%$ of respondents aged $18-24,8 \%$ of those aged $25-34,7.1 \%$ of respondents aged $35-44$, and $2.5 \%$ of people aged 45-54. On the other hand, the highest percentage $(23.5 \%)$ of people having no opinion on the subject was noticed among respondents aged 18-24.

The overall atmosphere of the particular running event is a decisive factor for $68.5 \%$ of the respondents. For $57.5 \%$ of the interviewees, an important factor is the landscape quality of a running trail. It was also observed that $37 \%$ of the respondents claim to choose events close to their place of living. The reputation of the event and opinions of other participants are important for $22.3 \%$ of the respondents. Other factors covered a low entry fee (17.3\%), the number of participants (11.8\%), and a starter kit (8.7\%). The presence of VIPs was considered to be the least important (1.7\%). The statistical analysis carried out shows that the preferences concerning factors determining the participation of respondents in the running event are differentiated by reference to gender, age, residence, and the number of years of running experience. Taking into account the sex of the respondents, it was noted that the differences concern such factors as the general atmosphere of the event $(C=0.102, p=0.56)$, the reputation of the event $(C=0.117, p=0.028)$, and safety reasons $(C=0.119$, with $p=0.026)$. For other factors, the percentage of males and females was similar (Fig. 1). Men were definitely more likely to point to "the general atmosphere of the event" and to "the reputation of the event" (71.8\% and $25.6 \%$ respectively). To compare, the above factors were preferred by $61.6 \%$ and $15.2 \%$ of women, respectively. The security of the event was pointed by $9.8 \%$ women and $3.8 \%$ men.

The respondents' views on factors determining their participation in the particular event also differed according to age (Fig. 2). The statistically significant difference concerns "the participation of VIPs" $(C=0.242, p<0.001)$. This factor was chosen by $1.8 \%$ of respondents aged $25-34,0.6 \%$ of those aged $35-44$, and $14.3 \%$ of the respondents aged 55 and older. The participation of VIPs was totally irrelevant for the respondents aged 18-24 and 45-54.

The respondents' place of residence also influenced their preferences in respect of factors affecting the de- 


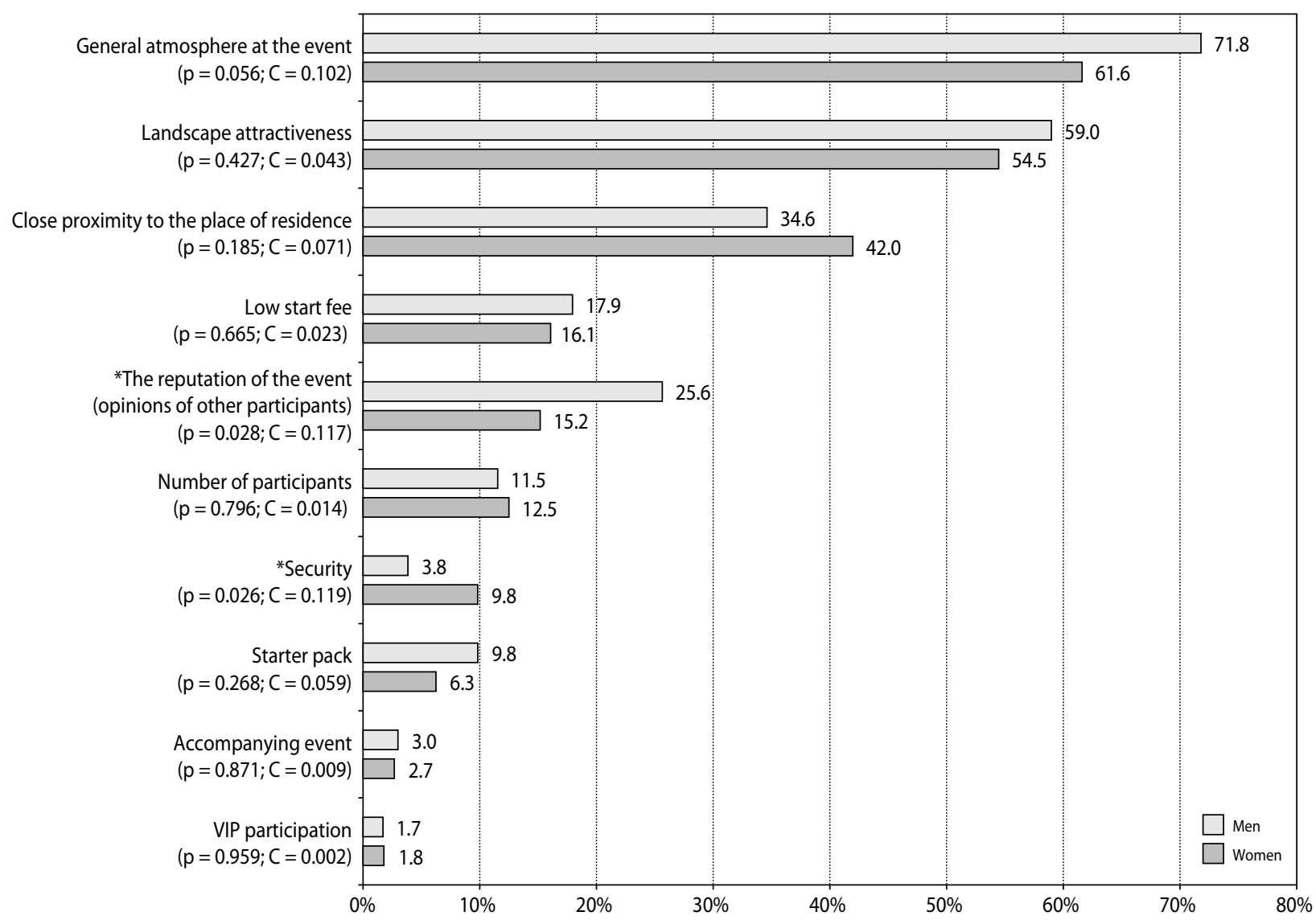

Figure 1. Comparison of the answers to the question "What prompts you to choose a specific running event" between men and women ( $p$ - probability of chi-square test, $C$ - coefficient of contingency, ${ }^{*}$ - statistically significant difference)

cision concerning participation in a particular event (Fig. 3). The statistically significant difference was associated with such factors as "the reputation of the event" $(C=0.150, p=0.045)$ and "a close distance from the place of residence" $(C=0.212, p<0.001)$. "The reputation of the event" was more important for residents of towns, whereas respondents from rural areas more frequently pointed to "a close distance from the place of residence." The highest percentage of respondents indicating "the reputation of the event" (38.2\%) was noted among respondents from cities with a population of 100,000 to 500,000 inhabitants. Similarly, the above was pointed by the respondents from towns with a population of less than 100,000 inhabitants $(24.4 \%)$ and above $500,000(21.6 \%)$. In contrast, the lowest number of respondents from rural areas pointed to this factor $(14.6 \%)$, whereas "a close distance from the place of residence" was the most frequent choice for people in this group. The distance from the place of residence was an important factor determining the participation in a specific running event for $44.1 \%$ of residents of towns with a population of 100,000 to 500,000 inhabitants, $37.8 \%$ of respondents living in towns up to 100,000 inhabitants, and $26.4 \%$ of those from cities with a population of 500,000, and above.

The preferences of respondents with regard to the above factors were significantly differentiated according to their running experience. The number of years of running influenced the interviewees' preferences regarding "the general atmosphere of the event" $(C=0.152, p=0.16)$, "a starter kit" $(C=0.218$, $p<0.001)$, "the landscape attractiveness of the running trail" $(C=0.134, p=0.041)$, and "the security of the event" $(C=0.195, p=0.01)$. Respondents with a long running experience more frequently pointed to "the general atmosphere of the event" $(52.2 \%, 66.7 \%$, and 


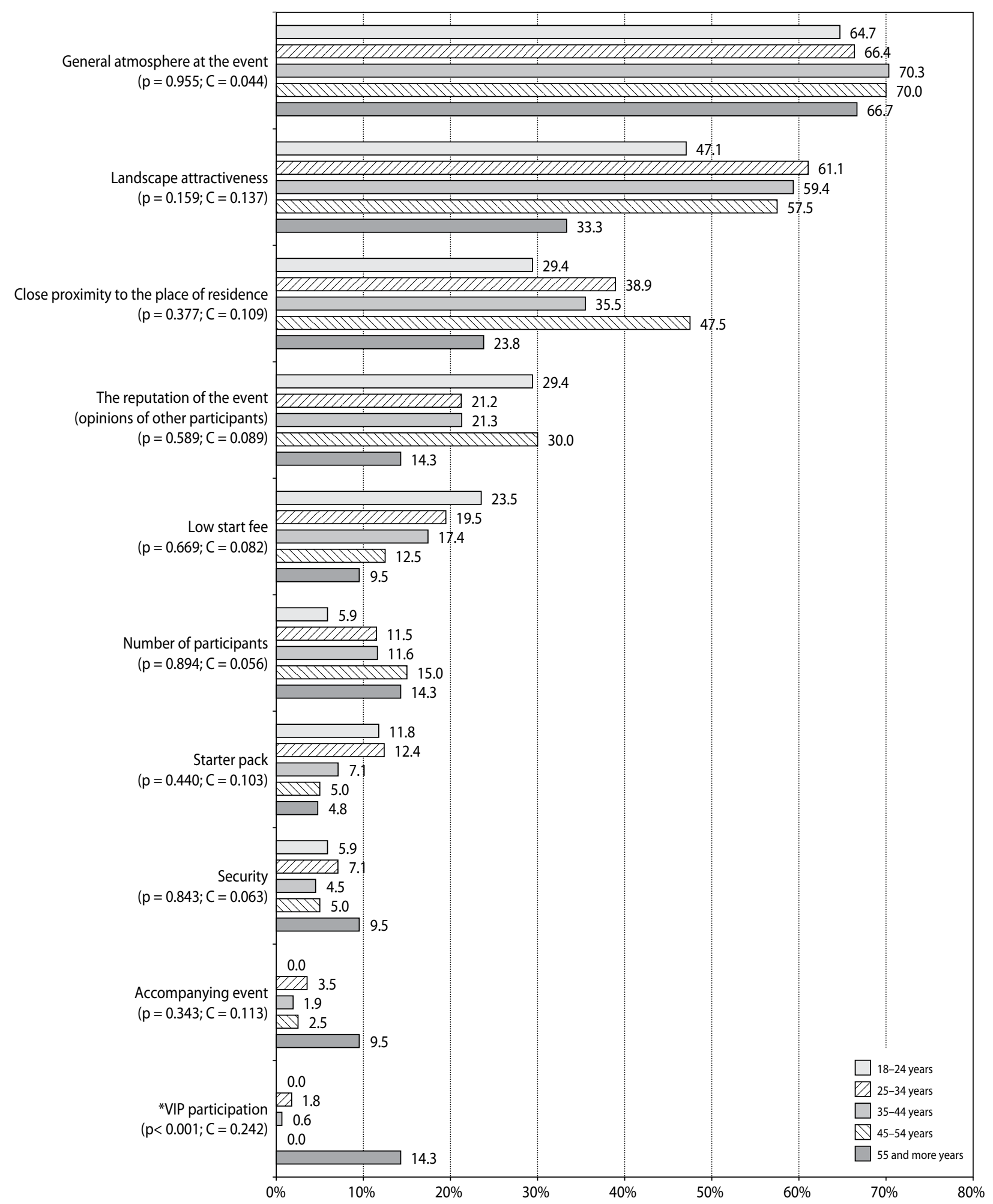

Figure 2. Comparison of the answers to the question "What prompts you to choose a specific running event" between age groups ( $p$ - probability of chi-square test, $C$ - coefficient of contingency, ${ }^{*}$ - statistically significant difference) 


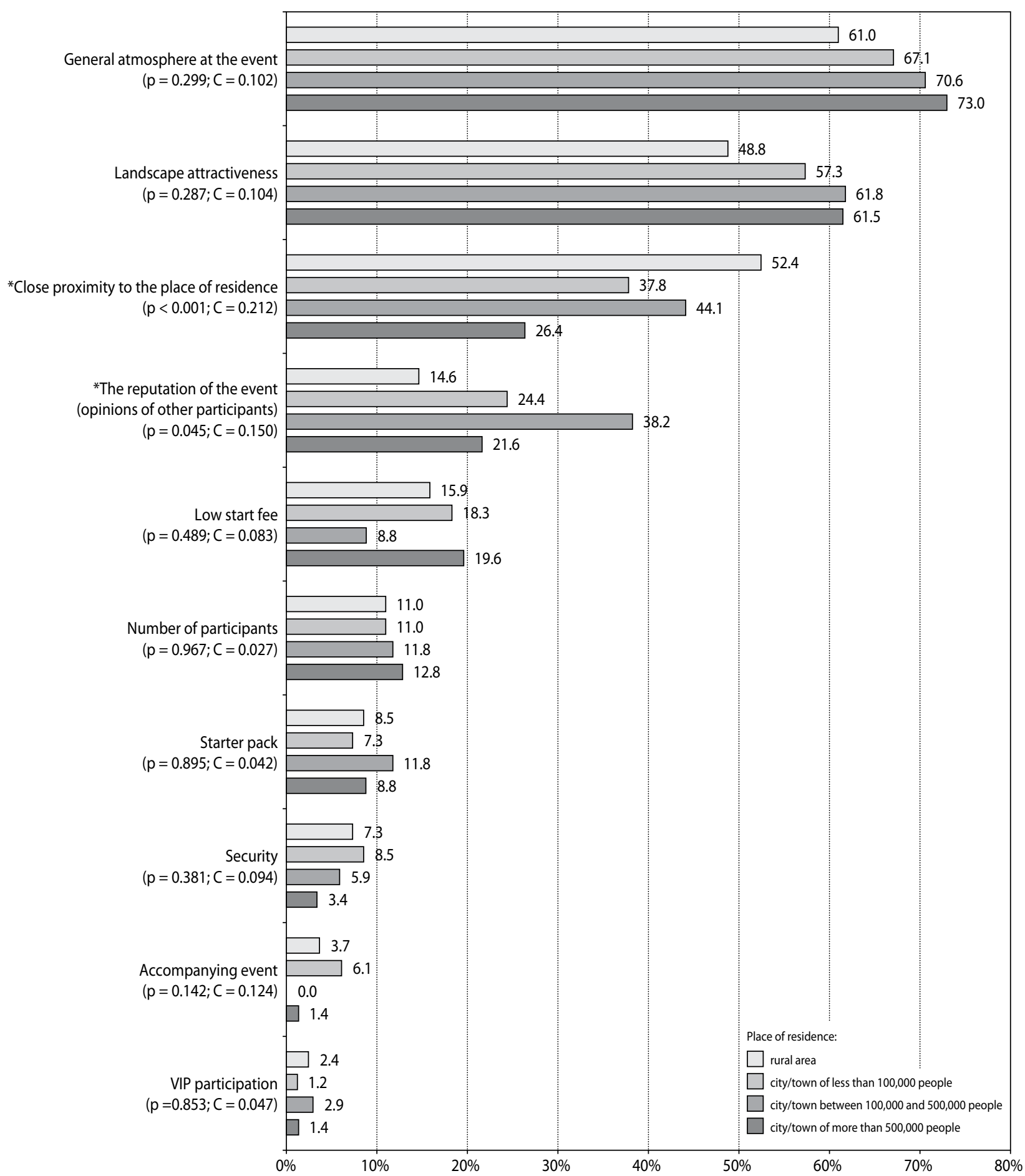

Figure 3. Comparison of the answers to the question "What prompts you to choose a specific running event" between respondents divided into groups with different place of residence ( $p$ - probability of chi-square test, $C$ - coefficient of contingency, ${ }^{*}$ - statistically significant difference) 
$73.7 \%$, respectively), as well as to "the attractiveness of the running trail" $(41.3 \%, 57 \%$, and $61.8 \%$, respectively) as important factors affecting their choice of the particular running event. The "starter kit" was the choice of $17.5 \%$ of respondents with a running experience from 2 to 4 years, $3.8 \%$ of those who have been running for 4 years, and $6.5 \%$ of respondents running for less than a year. The security of the event was indicated by $17.4 \%$ of the respondents who have been practicing running for less than a year, $2.6 \%$ of those who have been running from 2 to 4 years, and $4.8 \%$ of the respondents who have been practicing running for 4 years.

\section{Discussion}

In recent years, forests have become a very important source of non-wood products, as well as environmental, ecological, and social benefits. Many authors (e.g., Glük and Weiss 1996; Koch 1996; Eland and Wiersum 2001) believe that the role of forests in Western societies has changed dramatically, shifting from a productive to consumptive function (mainly recreational and landscape-related), as well as protective functions (biodiversity, erosion). The rising public expectations toward forests can be also observed in Poland as a trend toward reducing multiple functions of the forest to one, namely social function. In many areas, especially in the vicinity of urbanized areas, forests are perceived as a space that favors the satisfaction of recreation, relaxation, and sport-related needs. In Poland, the number of sports events - including those held in forests - is growing each year. Social studies carried out in the year 2013 have shown that running has become the most popular physical activity among Poles. What is more, it has become more popular than cycling, which had been favored the previous year (Dzięgiel and Lubowiecki-Vikuk 2013). However, according to the study carried out by Janeczko et al. (2016), when comparing the model of recreation in forests surrounding Warsaw in 2012 with the preferences in 2000, it can be seen that the interest in running in forests has decreased by $0.7 \%$ within this period.

The reasons for taking up particular sporting disciplines, as well as the forms of sport tourism, were discussed by such authors as Shipway and Joner (2007), Gibson (2005), Weed (2006), Wann et al. (1999), and
Getz and McConnell (2014). There are also multiple works on recreational functions of the forest. The preferences and expectations of various social groups with respect of tourism and recreation in forest areas are relatively well known (Vander Stoep and Duniavy 1992; Alberga and Dawson 1993; Hammitt and Patterson 1993; Janeczko 2002). The studies reveal for instance that forests are generally more frequently visited by men than by women (Šišak 1996). More frequent visitors are also persons between 15 and 29 years of age rather than elderly people (Šišak 1996; Lucas 1997). Among people older than 24 years of age, there is a steady decline in spending leisure time in forests as regarding participation in active forms of recreation (Dwyer 1993). Apart from this fact, forests are more often the place of rest for city dwellers rather than people from rural areas: Šišak (1996), Hammitt and Patterson (1993), Dwyer (1993).

As has been shown by the studies already carried out, people running in forests either for recreational reasons or taking part in sports events, are mostly men, middle-aged (35-44) or younger (25-34), city dwellers, and people with running experience that is longer than 4 years. These results are consistent with the findings of Dzięgiel and Tomanek (2014), Dusiński (2016), and Ogles and Masters (2003). Therefore, it shall be concluded that the profile of an average runner is similar to the profile of a person visiting a forest for recreational purposes.

The research has proven that among people running in forests, a large percentage $(70.2 \%)$ is represented by participants of running events held in forests. This may result from a number of reasons. First of all, the recent years have witnessed a significant increase in the number of sports events in Poland. The data provided by the State Forests, owning 77\% of forests in Poland, reveal that the number of running events held in forests in 2016 was several times higher compared to 2010. Only last year, more than 17,000 people took part in running events organized in forest areas near Gdansk, one of the largest urban agglomerations in Poland, and 15,000 people in forests surrounding Warsaw. Second, the studies carried out covered a very high percentage $(86.7 \%)$ of respondents with experience in running exceeding one year. Along with the increase in the period of running, the increase in the interest in participation in running events of various kind is observed, as has been proved by the study of Dusiński (2016). In addi- 
tion, men dominated the study (67.7\%). Numerous researchers have noticed (Gill et al. 1996; Ziegler 1991) that males tend to score higher on measures of competitiveness than females do. Hence, competitiveness, also in running, is the domain of men rather than women, which in turn leads to their higher participation in various competitions.

Important factors to be taken into consideration by respondents when making decisions concerning their participation in a particular running event were the general atmosphere of the competition and the attractiveness of the route. The general atmosphere was vital for all of the respondents. Similar results were obtained in the 2014 National Inventory of Runners. However, the attractiveness of a route was also the most frequently (77.7\%) indicated element determining the choice of destination by the respondents taking part in the study carried out by Dusiński (2016). Similarly, Tainio (2012) points out that environmental considerations, including the aesthetics of the surroundings and landscape are particularly important for leisure runners.

\section{Conclusion}

The growth in the popularity of running in Poland and, as a consequence, the increasing number of running events - also in forest areas - call for a thorough recognition of the needs and preferences of their participants. Studies that have been carried out suggest that the largest group of people running in forests are men, persons aged 35-44, residents of towns, with a long experience in running (over 4 years). The results show that forests in Poland are an attractive place for running. Participating in forest running events was determined by sex, residence, and experience. The age of respondents did not influence their views on the attractiveness of the forest as a place for sports, including the organization of running events. It was observed that the frequency of participation in running events increases together with experience. The attractiveness of the running event was mainly associated with its general atmosphere and the characteristics of the running trail. However, views were diversified according to sex, age, residence, and experience in running. The study also constitutes an important guidance for companies organizing running events. The more we learn about the reasons for the participation in forest running competitions, the better we can understand why so many people bear the costs of participating in such events. What is more, the study indicates that forest areas, especially those surrounding cities, through the development of sport and recreation serve the enhancement of health and well-being of society. Access to nature can be an important theme in promoting contemporary lifestylebased public health approaches.

\section{References}

Alberga, K.A., Dawson, C.P. 1993. Effects of seasonality and time of week on hiker motivations and satisfactions in the high peaks wilderness area. In: Proceedings of the 1993 Northeastern recreation research symposium, 18-20 April 1993, Saratoga Springs, NY. General Technical Report, NE-185, 119-122.

Ayres, J. 1979. Sensory integration and the child. Western Psychological Services, Los Angeles, USA.

Faber, T.A., Kuo, F., Sullivan, W. 2001. Coping with ADD: The surprising connection to green play settings. Environment and Behavior, 33 (1), 54-77.

Dusiński, M. 2016. Running tourism in Poland and its development. Master's thesis, Faculty of Economic Sciences, SGGW, Warsaw.

Dwyer, J.F. 1993. Customer diversity and the future demand for outdoor recreation. In: Proceedings of the 1993 Northeastern recreation research symposium, 18-20 April 1993, Saratoga Springs, NY. General Technical Report, NE-185, 59-63.

Dzięgiel, A., Lubowiecki-Vikuk, A. 2013. Running events as a specific type of sporting events. Zeszyty Naukowe. Turystyka i Rekreacja, 12 (2), 119-135.

Dzięgiel, A., Tomanek, M. 2014. The profile of a runner in mountain running competitions. Studia i Monografie AWF we Wroclawiu, 120, 88-102.

Elands, B.H.M., Wiersum, K.F. 2001. Forestry and rural development in Europe: an exploration of sociopolitical discourses. Forest Policy and Economics, 3, 5-16.

Getz, D., McConnell, A. 2014. Comparing trail runners and mountain bikers: motivation, involvement, portfolios and event-tourist careers. Journal of Convention and Event Tourism, 15 (1), 69-100. 
Gibson, H. 2005. Towards an understanding of why sport tourism do what they do. Sport in Society, 8 (2), 198-217.

Gill, D.L., Williams, L., Dowd, D.A., Beaudoin, C.M. 1996. Competitive orientations and motives of adult sport and exercise participants. Journal of Sport Behavior, 19, 307-318.

Gluck, P., Weiss, G. 1996. Forestry in the context of rural development: Future research needs. In: EFI Proceeding No. 15, 15-17 April 1996, Vienna, 173.

Hallmann, K., Kaplanidou, K., Breuer, C. 2010. Event image perceptions among active and passive sports tourists at marathon races. International Journal of Sports Marketing and Sponsourship, 12 (1), 32-47.

Hammitt, W.E, Patterson, M.E. 1993. Use patterns and solitude preferences of shelter campers in Great Smoky Mountains National Park U.S.A. Journal of Environmental Management, 38, 43-53.

Janeczko, E. 2002. Environmental and social determinants of recreational functions of the Mazowiecki Landscape Park, PhD thesis, Faculty of Forestry, SGGW, Warsaw.

Janeczko, E., Fialova, J., Tomusiak, R., Woźnicka, M., Janeczko, K., Budnicka-Kosior, J., Kwaśny, Ł. 2018. Attractiveness of running events in forests of Poland and Czech Republic (in Polish with English summary). Sylwan, 162 (7), 610-616.

Janeczko, E., Woźnicka, M., Tomusiak, R., Dawidziuk, A., Kargul-Plewa, D., Janeczko, K. 2016. Social preferences regarding recreation in forests of the Mazowiecki Landscape Park in 2000 and 2012 (in Polish with English summary). Sylwan, 161 (5), 422-429.

Koch, N.E. 1996. Forestry in the context of rural development: future research needs. In: EFI Proceedings No 15 (eds.: P. Gluck, G. Weiss), 9-12.

Lucas, O.W.R. 1997. Aesthetic considerations in British forestry. Forestry, 70 (4), 343-349.

Mitchell, R. 2013. Is physical activity in natural environments better for mental health than physical activity in other environments? Social Science and Medicine, 91, 130-134.
Moore, R., Wong, H. 1997. Natural learning: Rediscovering nature's way of teaching. MIG Communications, Berkeley, USA.

National Inventory of Runners 2014 - report (http:// polskabiega.sport.pl/pdf/nsb_raport.pdf)

Ogles, B.M., Masters, K.S. 2003. A typology of marathon runners based on cluster analysis of motivations. Journal of Sport Behavior, 26 (1), 69-85.

Shipway, R., Jones, I. 2007. Running away from home: understanding visitor experiences and behavior at sport tourism events. International Journal of Tourism Research, 9, 373-383.

Šišak, L. 1996. Frequention of forests by inhabitants of the Czech Republic. Lesnictvi - Forestry, 42 (6), 245-253.

Swarbrick, N., Eastwood, G., Tutton, K. 2004. Selfesteem and successful interaction as part of the forest school project. Support for Learning, 19 (3), 142-146.

Tainio, M. 2012. Artification of sport: the case of distance running. Contemporary Aesthetics, 4, 1-12.

Vander Stoep, G.A., Duniavy, L. 1992. Public involvement in developing park and open space recreation management strategies. Proceedings of the 1992 Northeastern recreation research symposium. General Technical Report, NE-176, 63-68.

Wann, D.L., Schrader, M.P., Wilson, A.M. 1999. Sport fan motivation: questionnaire validation, comparisons by sport and relationship to athletic motivation. Journal of Sport Behavior, 22 (1), 114-139.

Waśkowski, Z. 2014. Running as a form of women's active leisure time spending - motives, preferences and expectations. Marketing i Rynek, 11, 483-491.

Weed, M. 2006. Sports tourism and the development of sports events http://idrottsforum.org/all_articles/ weed/weed061213.html (accessed 05.01.2017).

Wells, N. 2000. At home with nature: Effects of "greenness" on children's cognitive functioning. Environment and Behavior, 32 (6), 775-795.

Ziegler, S.G. 1991. Perceived benefits of marathon running in males and females. Sex Roles, 25, 119-127. 